\title{
Complementação verbal no português do Libolo (Angola): uma descrição preliminar
}

\section{Preliminar description of verbal complementation in Libolo Portuguese}

\author{
Eduardo Ferreira dos Santos* \\ Universidade da Integração Internacional da Lusofonia Afro-Brasileira \\ São Francisco do Conde, Bahia, Brasil. \\ Kialunda Sozinho Kialanda** \\ Universidade da Integração Internacional da Lusofonia Afro-Brasileira \\ São Francisco do Conde, Bahia, Brasil.
}

\begin{abstract}
Resumo: A complementação verbal é um dos fenômenos que diferencia o português brasileiro (PB) do europeu (PE) em relação à realização dos objetos diretos e indiretos (DUARTE, 1986; CYRINO, 1993,1997; TORRES MORAIS; BERLINCK, 2007; entre outros). Trabalhos como os de Mingas (2000), Miguel (2003), Campos (2010) e Lopes, Souza e Alvarenga (2016) apontam algumas características da complementação verbal no português de Luanda, capital de Angola, como a ocorrência de objeto direto nulo, comum no PB; uso do clítico 'lhe' para objeto indireto, comum no PE, mas também o seu uso como objeto direto, comum no PB. Faz-se necessário, então, um estudo mais amplo da complementação verbal em demais variedades do português angolano, como a variedade falada no Libolo.
\end{abstract}

Palavras-chave: Português de Angola. Complemento Verbal. Sintaxe

Abstract: The verb complementation is one of the phenomena that differentiates the Brazilian Portuguese (PB) from the European Portuguese(PE) in cases of the realization of the direct and indirect objects (DUARTE, 1986; CYRINO, 1993, 1997; TORRES MORAIS; BERLINCK, 2007; among others). Researchs of the portuguese spoken in Luanda, capital of Angola, such as Mingas (2000), Miguel (2003), Campos (2010) and Lopes, Souza e Alvarenga bring to us some features of the verbal complementation in this portuguese variety such as the occurrence of a null direct object - common in PB; the use of the clitic 'him' for indirect object common in PE, but also used as direct object, common in PB. It is necessary, then, a more extensive study of the verb complementation in other varieties of Angolan Portuguese, like the variety spoken in Libolo.

Keywords: Angola Portuguese. Verb Complementation. Syntax.

\section{INTRODUÇÃO}

No âmbito dos trabalhos de descrição e análise linguísticas, o português figura entre as línguas em que se destacam diversas abordagens teórico-metodológicas para diferentes fenômenos linguísticos. A maioria desses trabalhos privilegiou, durante um longo período, aspectos do português brasileiro (doravante PB) e do português europeu (doravante PE). Esses estudos possibilitaram a delimitação de diferenças existentes entre a gramática do

* Doutor em Filologia e Língua Portuguesa pela Universidade de São Paulo (USP). Professor Universidade da Integraşão Internacional da Lusofonia Afro-Brasileira (UNILAB). E-mail: eduardo@unilab.edu.br.

** Licenciando em Letras e Língua Portuguesa, pela Universidade da Integração Internacional da Lusofonia Afro- Brasileira (UNILAB). E-mail: kialundaunilab@gmail.com 
PB e do PE, como no quadro dos pronomes, no uso das preposições, na ordem dos constituintes etc.

Considerando o continente africano, ressaltamos que a língua portuguesa é língua oficial de Angola, Cabo Verde, Guiné-Bissau, Guiné-Equatorial, Moçambique e São Tomé e Príncipe. Embora para cada um desses países o português apresente um status específico (língua materna, segunda língua ou apenas língua de relações comerciais), ainda não temos um número significativo de trabalhos que apontem para as especificidades do português aí falado e que aproximem, ou distanciem, as variedades africanas das variedades brasileira e europeia. Esses estudos são importantes porque contribuem na sistematização dos

diferentes "falares" de português nesses espaços, considerando três aspectos, a saber,
históricos, sociais e linguísticos, que nos ajudam a compreender a presença da língua
portuguesa em espaços tradicionalmente plurilíngues e inserida em um contexto colonial, e
que também nos auxiliam no (re)conhecimento de normas ou padrões linguísticos
particulares (SANTOS, 2018).

Os estudos comparativos entre o PB e o PE mostraram que a complementação verbal é realizada de maneira distinta para os objetos diretos e indiretos - ou, respectivamente, acusativos e dativos - nessas duas variedades (DUARTE, 1986; CYRINO, 1993,1997; TORRES MORAIS; BERLINCK, 2007; entre outros). Para o português falado em Angola, em específico, Luanda, temos os trabalhos de Mingas (2000), Miguel (2003), Campos (2010) e Lopes, Souza e Alvarenga (2016) que trazem algumas características dessa complementação verbal, como a ocorrência de objeto direto nulo, comum no PB; uso do clítico 'lhe' para objeto indireto, comum no PE, mas também o seu uso como objeto direto, comum no PB.

Para o presente trabalho, destacaremos a complementação verbal do português falado no município do Libolo, província de Cuanza Sul, a partir dos dados do português do Libolo (doravante PLB). Buscamos abranger um maior alcance dos estudos descritivos do português falado em Angola, para além da capital, contribuindo para a ratificação das evidências que apontam para uma especificidade da variedade angolana da língua portuguesa, assim como já temos para o PB e PE.

Na seção 2, logo após essa Introdução, apresentamos uma revisão da literatura acerca da complementação acusativa e dativa no português. $\mathrm{Na}$ seção 3, faremos uma breve apresentação dos aspectos sociolinguísticos do município do Libolo. Para a seção seguinte, reservamos a descrição da complementação verbal no PLB a partir dos dados levantados, seguida das considerações finais e referências bibliográficas.

\section{CONSIDERAÇÕES SOBRE A COMPLEMENTAÇÃO VERBAL NO PORTUGUÊS}

Diversos trabalhos na literatura linguística apontaram as diferenças na gramática do PB e do PE, como no quadro dos pronomes, no uso das preposições, na ordem dos constituintes etc. A realização dos complementos verbais objeto direto (OD) e do objeto indireto (OI) também já foi abordada nessas duas variedades e é apontada como um dos 
fatores que as diferenciam (DUARTE, 1986; CYRINO, 1993,1997; TORRES MORAIS; BERLINCK, 2007; entre outros).

Os complementos verbais podem ser classificados como argumentos preposicionados (OI) e não-preposicionados (OD). A natureza desses elementos está diretamente relacionada aos tipos de verbos veiculados nessas sentenças. Destacaremos dois tipos de verbos: transitivos e bitransitivos.

Conforme apontam Cyrino, Nunes e Pagotto (2009, p. 58), os verbos transitivos são exemplificados pelos verbos de ação usados na voz ativa. A posição de especificador do sintagma verbal (SV) é ocupada pelo agente e o complemento de V é ocupado pelo paciente $e^{1}$ :

(1) lá nós COMEMOS um quindim (...). (DID RJ 328)

Os verbos bitransitivos são apontados pelos mesmos autores como os que envolvem um argumento externo e dois argumentos internos. Tipicamente, são os verbos de transferência de posse e os verbos de posicionamento:

(2) aí eu fico trabalhando em casa (...) para... levar um ao banheiro para DAR uma comida para outro. (D2SP360)

(3) há um determinado momento em que eu VOU COLOCAR resumo na translação. (EF POA 278)

$\mathrm{Na}$ língua portuguesa, os complementos diretos são os sintagmas nominais (DPs) que ocorrem em sentenças transitivas (1) e em sentenças bitransitivas (2) e (3). Sua representação se dá por um DP, um CP e também por um IP, recebendo do verbo o papel temático de tema/paciente, como em $(4)^{2}$ :

(4) a. Ricardo DISSE algumas palavras.

b. Ricardo DISSE que comprou alguns brinquedos.

c. Ricardo DIZ ter comprado alguns brinquedos.

Considerando a noção de caso e a obrigatoriedade do DP ter seu caso marcado, a caracterização do OD no português também se dá a partir da ordem dos termos em uma sentença, já que não é licenciada a marcação morfológica de caso. Segundo Cavalcante e Figueiredo (2009, p. 94-95), no PB vernacular, essa característica é a que permite o uso do pronome sujeito na posição de OD, como em (5) e (6):

(5) Ai, saudade, LEVA en.

(6) O João, ENCONTREI ele no cinema ontem.

\footnotetext{
${ }^{1}$ Os dados de (1) a (3) são retirados dos autores e renumerados, mantendo a indicação do código dos informantes, conforme publicação original.

${ }^{2}$ Os dados de (4) a (7) são de Cavalcante e Figueiredo (2009, p.94-97), renumerados.
} 
Em (5) e (6), os pronomes nominativos "eu" e "ele" são interpretados como OD, pois ocupam a posição interna a VP, identificando-os como acusativo.

No processo de passivização das construções com verbos transitivos diretos, o OD ocupa a posição de sujeito da sentença e o sujeito ou agente pode não ser mencionado:

(7) a. As decisões FORAM ADIADAS pela diretoria.

b. ADIARAM-SE as decisões.

c. FICARAM ADIADAS as decisões.

O OD também pode retomar um referente mencionado anteriormente no discurso, chamado de OD anafórico, ou pode ser suprimido ao referir-se a um referente do contexto situacional, como vemos em (8) e (9), respectivamente ${ }^{3}$ :

(8) Acho que a criança(i) deve ir o mais cedo possível a escola (né)?... e... uma coisa que eu não me arrependi foi TER BOTADO ela(i) com um ano e quatro meses... (DID SSA 98)

(9) (...) daí ela $a_{(i}$ sai pra ser alfabetizada... o meu problema agora é onde BOTAR [Ø] (i pra ser alfabetizada... se eu BOTARIA [Ø] (i logo num colégio como eu fiz. (DID SP234)

Segundo Cavalcante e Figueiredo (2009, p. 98), o português dispõe de quatro estratégias para retomar na função de OD um elemento mencionado anteriormente no discurso:

I) Clítico (CL):

(10) Ana $_{(i)}$ chegava por uma rua pouco iluminada, mas eu a $a_{(i)}$ VIA longe.

II) Objeto nulo (ON):

(11) Vi o carro de meus sonhos $(i)$ em uma exposição, mas não pude COMPRAR

III) Pronome nominativo ELE/ELA (PR):

(12) $\operatorname{Rita}_{(i)}$ me convidou para uma viagem, mas eu não PUDE ACOMPANHAR $\operatorname{ela}_{(i)}$.

IV) Sintagma nominal (DP):

(13) Doce pronto $_{(i)}$ tem em qualquer lugar. Mas algumas pessoas teimam em FAZER doce $(i)_{(i)}$ em casa.

\footnotetext{
${ }^{3}$ Dados de Cyrino, Nune se Pagotto (2009, p.68), renumerados. A indicação do código dos informantes foi mantida conforme a publicação original.
} 
Nos dados de (10) a (12), temos exemplos de estratégias em que os elementos não possuem autonomia discursiva, sendo interpretados apenas quando são correferentes a um elemento presente no discurso. O dado (13) exemplifica uma expressão referencial que não exige antecedência caracterizando-se como referencialmente autônoma.

Assumindo que as estratégias de manifestação do OD anafórico distinguem as gramáticas das línguas, podemos notar diferenças nas variedades brasileira e europeia. Para o PE, apenas as estratégias de CL e ON estariam disponíveis, segundo Cavalcante e Figueiredo (2009, p.99), enquanto no PB ocorrem as três estratégias de retomada do OD - CL, ON e PR - e, de acordo com os autores, há um caso cada vez mais frequente do pronome forte 'ele/ela' para a função de OD. No português de Luanda, atesta-se a ocorrência da estratégia PR, como apontado por Miguel ${ }^{4}$ :

(14) Eu CONVIDO ela para ir connosco.

Figueiredo (2004) ao estudar comunidades afro-brasileiras do interior da Bahia, aponta a ausência total da estratégia CL, analisada como uma forma não-vernacular e adquirida em contexto de escolarização.

O complemento dativo (ou OI) é o argumento verbal presente nas construções bitransitivas e com papel semântico de alvo/meta/fonte, realizado por um sintagma nominal (DP) introduzido pela preposição A ou por um elemento clítico. No PB e no $\mathrm{PE}$, a realização do complemento dativo não ocorre de maneira semelhante considerando i) a possibilidade de redobro; ii) a presença e o tipo de preposição introdutora; iii) a natureza do pronome usado em contexto anafórico (CAVALCANTE; FIGUEIREDO, 2009, p.119).

No PE, o complemento dativo é realizado, na maioria dos casos, como um sintagma nominal introduzido pela preposição 'a':

(15) O João COMPROU uma bola ao Pedro.

Em (15), o sintagma preposicionado 'ao Pedro' é o argumento dativo, com uma dupla leitura de origem ou ponto final do movimento de compra. Ao substituir a preposição 'a' por 'para', temos uma leitura de beneficiário da ação de comprar e com função de adjunto adverbial:

(16) O João COMPROU uma bola para o Pedro.

Segundo Campos (2010, p. 44) - o dado está renumerado -, no português de Luanda, a forma preferencial do complemento dativo é com a preposição 'a':

(17) ESTAMOS A DESEJAR bom fim de semana a todos.

${ }^{4}$ Miguel (2003, p. 64), dado renumerado (a escrita do termo "connosco" respeita a forma usada pela autora). 
Em seu trabalho, contudo, foi registrada uma ocorrência de complemento dativo introduzido pela preposição 'para', conforme vemos em (18), extraído do autor:

(18)nós utilizamos filtro de areia, a camada de areia então é filtrada [...] depois de apanhar o cloro é que vai para a cisterna, e aí é que se VAI DISTRIBUIR para a população.

O redobro do complemento dativo também é uma forma de caracterizar o PE, através da forma clítica 'lhe', obrigatória diante do sintagma dativo introduzido pela preposição ' $a$ ':

(19) a. DEI-lhe o livro a ela.

b. *DEI o livro a ela.

c.*DEI-lhe o livro para ela.

Torres Morais e Berlinck (2007) apontam para o PB duas mudanças na realização dos complementos dativos quando comparadas ao PE. Segundo as autoras, o PB apresenta i) perda quase completa do pronome clítico de terceira pessoa 'lhe(s)', que ocorre substituído pelo pronome forte 'ele/ela' introduzido pela preposição ou não é realizado; ii) variação entre as preposições 'a' e 'para', com uso frequente da segunda.

Para Figueiredo Silva (2007), o uso da preposição 'para' em lugar da preposição 'a', no $\mathrm{PB}$, resulta em uma estrutura de adjunto, justificando a perda do clítico dativo 'lhe' apontado por Torres Morais e Berlinck (2007). No entanto, a autora justifica uma extensão do emprego do clítico 'lhe' na pronominalização do OD de segunda pessoa no lugar dos acusativos 'o/a'. Desse modo, haveria uma recategorização do clítico 'lhe' no PB e não o seu apagamento.

Em relação à mudança das preposições introdutora dos dativos, precisa-se considerar a não-realização da preposição. Cavalcante e Figueiredo (2009, p. 122) apontam que essa ausência de preposição em DPs ativos é rara no PB e no PE, sendo agramatical ou marginal em alguns dialetos. No entanto, os autores mostram que há documentação desse tipo de construção no dialeto da Zona da Mata de Minas Gerais (20) e de comunidades afro-brasileiras, como Helvécia (21):

(20) DÁ o recado o seu irmão! [Dá o recado ao seu irmão!]

(21) É... VINHA DÁ ele recado certim. [É... vinha dar a ele recado certim]

Cavalcante e Figueiredo (2009, p. 125) também mostram a partir de Oliveira (2005), que a ausência de preposição no complemento dativo está presente no português falado em Moçambique:

(22) Os jovens SÃO DADOS responsabilidades de família. [Aos jovens são dados responsabilidades de família]

${ }^{5}$ Cavalcante e Figueiredo (2009: 120), dados renumerados. 


\section{O MUNICÍPIO DO LIBOLO (CUANZA SUL - ANGOLA): BREVE ASPECTOS SOCIOLINGUÍSTICOS}

Ao tratarmos da língua portuguesa em África, e consequentemente, em Angola, é necessário abordar o início da chegada dos portugueses nesse território, o que remonta a meados do século XV e as incursões dos portugueses para territórios além-mar que se deram no contexto conhecido como "Era dos Descobrimentos", impulsionadas por fatores de ordens religiosa, econômica, estratégica e política (DIAS, 1989, p. 281).

$\mathrm{O}$ início da presença portuguesa no território que hoje equivale a atual divisão política de Angola dá-se no período de 1482 a 1484, a partir da liderança de Diogo Cão que estabelece contato com a unidade política do Reino do Congo e com as regiões de Ndongo e Matamba (FIGUEIREDO, 2015).

Em relação ao Libolo, vale destacar que diversas tentativas de ocupação da região foram mal sucedidas, como parte de uma política de colonização do interior de Angola. Durante três séculos, o interior angolano permaneceu sem uma ocupação efetiva dos portugueses, até meados do século XIX quando se intensificam uma (re)tomada colonial da África pelas potências europeias de então e a necessidade de uma ocupação do território. No Libolo, essa ocupação começa a ocorrer de forma sistemática em 1840 até a instalação da Missão Católica de Santo Antonio de Calulo, em 1893 (SANTOS, 2015).

Angola apresenta um grande contingente populacional pertencente ao grupo linguístico banto, que se reparte em grupos linguísticos distintos em termos numéricos e que acentuam a existência de relações entre etnia, língua e cultura, delimitando os agrupamentos etnolinguísticos e explicitando a diversidade linguística angolana (REDINHA, 2009, p. 18-19).

O município do Libolo é uma região ambundo em que se encontram falantes do quimbundo L1, variedade libolo, além da variedade designada por alguns habitantes das comunas de Calulo e Quissongo, como ngoya. O município é uma zona de confluência de falantes de quimbundo kissama e kibala, além de falantes da língua songo. O município também está ao alcance de regiões ovimbundo, com falantes da língua umbundo (FIGUEIREDO, 2018, p. 80).

Segundo Figueiredo (2018, p. 82), sendo a colonização angolana processada em zonas vizinhas do mar, e o interior quase inexplorado, propiciaram-se condições para a ocorrência de uma situação de diglossia linguística, com uma pequena elite afroportuguesa bilingue, restringindo o uso do português nos centros urbanos, e uma parcela significativa de falantes monolíngues nas suas línguas maternas e habitando nas zonas rurais e interioranas do país.

Os confrontos constantes para a ocupação do território e o isolamento do município durante a guerra pós-colonial fizeram com que no Libolo

acontecesse quer a defesa e preservação de ideologias autóctones quer a conservação de tradições socioculturais milenares e de marcas linguísticas específicas dos seus falantes, com o português falado por estes denotando a incorporação de substanciais traços morfossintáticos da L1 quimbundo (FIGUEIREDO, 2018, p. 83). 
É no século XX que o português se torna a língua mais falada em Angola, devido ao aumento de colonos portugueses no país e ao desenvolvimento dos centros urbanos angolanos. $\mathrm{Na}$ segunda metade do século, ocorre uma generalização da língua portuguesa em Angola, considerada língua de cultura e tecnologia, sendo as línguas locais africanas consideradas obstáculos para uma unidade nacional (MIGUEL, 2003, p. 26).

No Libolo, podemos notar essa efetivação da presença da língua portuguesa, evidenciando que o português deixa de ser exclusivamente uma língua do meio urbano e elitista, para ser a língua de uso e materna das pessoas. É a língua ensinada nas escolas locais de forma oficial, presente nos meios de comunicação e dos órgãos oficiais do município. Segundo Nzau (2011, p. 113), “este clima não remete apenas para um caráter irreversível de expansão territorial, como também pela outras reflexões que envolvem questões tais como a naturalização, nacionalização linguísticas e democratização do ensino".

\section{A COMPLEMENTAÇÃO VERBAL NO PLB}

Conforme apontam Cyrino, Nunes e Pagotto (2009, p. 58), os verbos transitivos são exemplificados pelos verbos de ação usados na voz ativa. A posição de especificador do sintagma verbal (SV) é ocupada pelo agente e o complemento de V é ocupado pelo paciente. No PLB, há a realização de verbos transitivos, como vemos nos exemplos a seguir, retirados de nosso corpus ${ }^{6}$ :

(23) Eu AJUDO a minha mãe. [HALDOM2]

(24) LAVÁ os pratos, FAZÊE tarefa. [LUSAMH1]

Em (23) e (24), os complementos verbais do verbo 'ajudar', 'lavar' e 'fazer' são, respectivamente, 'a minha mãe', 'os pratos' e 'tarefa'.

Para os mesmos autores, os verbos bitransitivos são classificados como os que envolvem um argumento externo e dois argumentos internos. Tipicamente, são os verbos de transferência de posse e os verbos de posicionamento. O dado abaixo, do PLB, ilustra um verbo bitransitivos:

\footnotetext{
${ }^{6}$ Nosso corpus é constituído de material coletado em viagens de campo ao município do Libolo, Cuanza Sul, Angola, no âmbito do "Projeto Libolo". O projeto "Município do Libolo, Kwanza Sul, Angola: aspectos linguístico-educacionais, históricoculturais, antropológicos e sócio-identitários”, também conhecido como "Projeto Libolo", é parcialmente financiado pela Universidade de Macau e por entidades privadas filantrópicas de Angola. Trata-se de um projeto internacional e multidisciplinar cujos pesquisadores intervêm, de forma articulada, em pesquisas nas áreas de Linguística, História, Antropologia, Filologia e Acções Pedagógicas. O "Projeto Libolo" está devidamente patenteado pelo Centro de Investigação e Desenvolvimento (R\&DAO) da Universidade de Macau, sob o número de referência SRG011-FSH13CGF, encontrando-se, desta forma, ao abrigo da vigente proteção de direitos autorais de propriedade intelectual designada por "Copyright (C) 2016, R\&DAO University of Macau”. Ao lado de cada dado é apresentada uma sequência de letras e números, ou apenas números, que apontam aspectos sociolinguísticos que identificam cada informante/gravação do banco de dados do Projeto.
} 


\section{(25) Só que num te DEI nenhuma dica. [MARANO10]}

Em (25), o argumento externo do verbo 'dar' embora não se faça realizado na sentença, pode ser aferido pela flexão do verbo na primeira pessoa do pretérito ('dei'), ou seja, 'eu'. Os dois argumentos internos são 'nenhuma dica' e o 'te'. Nota-se, assim, a característica de transferência de posse, típica desse verbo.

$\mathrm{Na}$ língua portuguesa, os complementos diretos são os sintagmas nominais (DPs) que ocorrem em sentenças transitivas (26) e (27) e em sentenças bitransitivas (28). No PLB, sua representação também se dá por um DP, um CP e também por um IP:

(26) Só... TEMO... TEMO cin... cin... TEMO cincos irmãs. [HALDOM2]

(27) DISSESTE que você ia pegar uma cena meu. [MARANO10]

(28) Lá FAZIA limpar o chão. [HALDOM2]

No dado (26), o complemento direto do verbo 'ter' é o sintagma determinante (DP) 'cincos irmãs'. O exemplo em (27) mostra que a complementação é feita por uma conjunção integrante (que/CP) introduzindo uma oração com função de OD. Em (28), a complementação verbal direta é assinalada pelo termo ‘limpar o chão’ (IP), um verbo em sua forma infinitiva.

Em relação à posição ocupada pelo OD, nas sentenças passivas com verbos transitivos diretos, notamos que, assim como no PB (CAVALCANTE; FIGUEIREDO, 2009, p. 97), no PLB encontramos a posição de sujeito preenchida pelo OD e o agente não é mencionado:

(29) Luanda FICOU ABARROTADA. [ANPAVM4]

(30) A fu- a makoka É LEVADA na moagem. [ANPAVM4]

Nos dados (29) e (30), do PLB, a posição de sujeito é ocupada pelos termos 'Luanda' e 'a makoka' que são os complementos verbais de seus respectivos verbos, ou seja, 'abarrotar' e 'levar'. Nos dois casos, o agente não é mencionado, característica das construções na voz passiva.

Para a retomada de um elemento mencionado anteriormente na função de OD, análises das variedades brasileira e europeia do português (CAVALCANTE; FIGUEIREDO, 2009, p. 98) apontam quatro estratégias para essa retomada: i) clítico (CL); ii) objeto nulo (ON); iii) pronome nominativo 'ele/ela' (PR) e iv) sintagma nominal (DP). Vejamos a ocorrência dessas estratégias nos dados do PLB:

(31) INF: Tou este ano... este ano não... este ano porque disseram... tiveram a falar se não tem... quem num tem cédula ${ }_{(i)}$ não estuda...

DOC1: Ham... você...

INF: ...não posso este ano que não tou a estudar.

DOC1: Você TEM cédula $a_{(\mathrm{i})}$ ?

INF: Não, num tenho(i ainda). [HALDOM2] 
(32) avô Camanga (i) fundou mesmo o baire já está morto até VER ele $e_{(\mathrm{i})}$ com mínimo mesmo respeito. [007A_160721_1229]

(33) Vamos respeitar o soba... Soba $a_{(i)}$ é pai grande... Respeito Aquele eu jurei mesmo assim RESPEITEI muito o pai(i) . [007A_160721_1229]

No dado (31), estamos diante de um caso de $\mathrm{ON}$, em que a informante, em sua última fala, não realiza o complemento 'cédula', já mencionado anteriormente em seu discurso e do documentador. Em (32), o pronome nominativo 'ele' é realizada na função de OD do verbo 'ver', quando a norma padrão preconiza o uso da forma acusativa 'o', isto é, “... já está morto até vê-lo com mínimo mesmo de respeito”. Tanto em (31) como em (32), as estratégias mostram que os termos não possuem autonomia discursiva e são interpretados apenas quando são correferentes a um elemento previamente explicitado. O dado em (33) apresenta o sintagma nominal 'o pai' retomado como OD de 'respeitar', mas que é referencialmente autônomo. Vale destacar que em nosso corpus não foi encontrada a estratégia de CL, que retomaremos adiante.

Assumindo que as estratégias de manifestação do OD anafórico distinguem as gramáticas das línguas, podemos notar diferenças nas variedades brasileira e europeia. Para o PE, apenas as estratégias de CL e ON estariam disponíveis, segundo Cavalcante e Figueiredo (2009, p. 99), enquanto no PB ocorrem as três estratégias de retomada do OD CL, ON e PR. Desse modo, parece-nos que o PLB aproxima-se do PB na presença da estratégia PR, como vimos em (32). Reforçamos que a mesma estratégia é encontrada no português de Luanda, conforme apontamos em (14), aqui retomado e renumerado:

(34) Eu CONVIDO ela para ir connosco.

Em relação a estratégia CL, nosso corpus não atestou sua ocorrência. Esse fato parece-nos ser característico do PLB, como já levantado por Figueiredo e Oliveira (2013, p. 48-52) para a mesma variedade. Os autores chamam a atenção para que essa estratégia aparece em falantes com grau de instrução mais elevado, ou seja, essa estratégia é adquirida tardiamente e através de uma educação formal. Figueiredo (2004), ao estudar comunidades afro-brasileiras do interior da Bahia, também aponta a ausência total da estratégia CL sendo analisada como uma forma não-vernacular e adquirida em contexto de escolarização.

Em relação ao complemento dativo (ou OI), considerando sua ocorrência a partir i) da possibilidade de redobro; ii) da presença e o tipo de preposição introdutora; e iii) da natureza do pronome usado em contexto anafórico (CAVALCANTE; FIGUEIREDO, 2009 , p. 119), conforme apontamos na seção 1, vejamos seu comportamento no PLB. Em nosso corpus, não encontramos a realização do redobro do clítico para o PLB, aproximando-o do PB.

A realização dos complementos dativos no PLB pode ser atestada a partir das seguintes características:

LHE - objeto indireto 
(35) Agora... agora como ARRANJEI-lhes já um outro vigilante. [ANPAVM4]

LHE - objeto direto

(36) [pediram três filhos à minha mãe $e_{(i)}$ pra lhes (i) $_{(i)}$ AJUDAREM. [ANPAVM4]

PREPOSIÇÃO 'A'

(37) DOU um salário ao rapazinho que fica lá a tomar conta das crianças. [ANPAVM4]

\section{PREPOSIÇÃO 'PARA'}

(38) Ele fica com essa preocupação e MANDA pra mim e eu venho entregar ao soba Paulo. [PAVARH5]

\section{PREPOSIÇÃO 'EM'}

(39) As mãe antigamente vai adivinhá pa ver se apanha a doença que... que... que dá no... na criança. E aí vai ali, quando sai ali e então o quimbanda arranja um... um medicamento $_{(i)}$ dos pau e vem te... e DAR $\varnothing_{(\text {(i) }}$ na criança. [TEMALM3]

Conforme apresentamos na seção 1, Torres Morais e Berlinck (2007), ao contrastarem o PB e o PE, apontam para duas mudanças na realização dos complementos dativos. O PB apresenta i) perda quase completa do pronome clítico de terceira pessoa 'lhe(s)', substituído pelo pronome forte 'ele/ela', introduzido pela preposição ou não realizado; e ii) variação entre as preposições 'a' e 'para', com uso frequente da segunda.

Não generalizamos as duas características apontadas pelas autoras presentes no PB para o PLB, considerando a incipiente pesquisa para essa variedade africana do português. No entanto, podemos destacar no PLB a sua aproximação com estratégias presentes no $\mathrm{PB}$, mas ausentes no PE.

Para Figueiredo Silva (2007), o uso da preposição PARA em lugar de A, no PB, resulta em uma estrutura de adjunto, justificando a perda do clítico dativo LHE apontado por Torres Morais e Berlinck (2007). No entanto, a autora justifica uma extensão do emprego do clítico LHE na pronominalização do OD de segunda pessoa no lugar dos acusativos $\mathrm{O} / \mathrm{A}$. Desse modo, haveria uma recategorização do clítico LHE no PB e não o seu apagamento. No PLB, há registros do uso do LHE como OD:

(40) eles chegaram aqui, lhes levaram até lá nos capim. [JOMICH3]

Cavalcante e Figueiredo (2009, p. 122), em relação à mudança das preposições introdutora dos dativos, chamam a atenção que precisamos considerar a não-realização da preposição, que é rara no PB e no PE em DPs ativos, sendo agramatical ou marginal em alguns dialetos. Nas falas da Zona da Mata de Minas Gerais e de comunidades afrobrasileiras baianas, como Helvécia, atesta-se esse tipo de construção, como mostramos

${ }^{7}$ Figueiredo e Oliveira (2013, p. 148; dado 45 renumerado). 
pelos dados (20) e (21), na seção 1. No dado apresentado em (22), do português de Moçambique, retomado em (41), também encontramos a não-realização da preposição:

(41) Os jovens SÃO DADOS responsabilidades de família.

No PLB, essa construção de ausência da preposição no complemento dativo pode ser vista abaixo:

(42) INF: Cinquenta (kwanzas)... Não tem. O pai prefere guardar o dinheiro (i) que sabe-se lá para que é...

DOC: Pois...

INF: do que dar $\varnothing_{(i)}$ eh pá. Mas então você a deixar... entrar assim as crianças prontos. E comecei eu mesma a PAGAR $\varnothing_{(i)}$ os vigilantes $^{8}$. [ANPAVM4]

\section{CONSIDERAÇÕES FINAIS}

Embora não fosse nosso escopo um levantamento exaustivo das construções que apresentassem complementação verbal, pudemos apresentar um conjunto de construções que podem nos ajudar, mesmo que preliminarmente, a apontar algumas características do PLB: o seu afastamento do PE quando do uso da estratégia de CL para a complementação direta e sua aproximação do $\mathrm{PB}$ no uso de PR. Na complementação dativa, há o uso concomitante das preposições 'a' e 'para', necessitando de estudos quantitativos para verificarmos sua frequência de uso, assim como o uso da preposição 'em'.

Também pudemos notar que o PLB, falado em uma região fora do eixo capital, também possui características do português falado em Luanda. Chamou-nos a atenção a não-realização da preposição introdutora de dativos no PLB e sua aproximação de variedades de português consideradas 'não standard', como a da Zona da Mata mineira e de variedades afro-brasileiras, como as faladas em comunidades remanescentes de quilombos, além de variedades africanas do português, como a moçambicana. Esse fato ratifica a importância de novos estudos descritivos do português falado, não só em Angola, e o tratamento analítico desses tipos de construções, contribuindo, inclusive, para se inferir o papel do contato linguístico na formação dessas variedades.

\section{REFERÊNCIAS BIBLIOGRÁFICAS}

CAMPOS, E.A. Notas sobre a expressão do objeto indireto no português angolano. In: MARÇALO, M.J. et al. (eds.). Língua portuguesa: ultrapassar fronteiras, juntar culturas. Évora: Universidade de Évora, 2010, p.34-49.

\footnotetext{
${ }^{8}$ No dado (42), o verbo 'pagar' é bitransitivo, ou seja, apresenta uma estrutura sintática básica [S V SN (SP)]. Embora o complemento direto (SN), 'dinheiro', não esteja realizado, é retomado no contexto, e seu complemento indireto (SP), 'os vigilantes' é realizado com a ausência de preposição ('a' ou 'para'), não interferindo na sua função semântica de 'alvo'.
} 
CAVALCANTE, R.; FIGUEIREDO, C. Complementos verbais diretos e dativos. In: LOBO, T. \& OLIVEIRA, K. África à vista. Dez estudos sobre o português escrito por africanos no Brasil do século XIX. Salvador: Edufba, 2009, p. 90-137.

CYRINO, S.M.L. Observações sobre a mudança diacrônica no português do Brasil: objeto nulo e clíticos. In: ROBERTS, Ian; KATO, Mary A. (Org.). Português Brasileiro: uma viagem diacrônica. Campinas, SP: Editora da Unicamp, 1993, p. 163-184.

CYRINO, S.M.L. O objeto nulo no português do Brasil: um estudo sintático-diacrônico. Londrina: Editora da UEL, 1997.

CYRINO, S.M.L.; NUNES, J.; PAGOTTO, E. Complementação. In: KATO, M. \& NASCIMENTO, M. (Org.). Gramática do português culto falado no Brasil: a construção da sentença. Vol III. Campinas: Editora da Unicamp, 2009, p. 47-96.

DIAS, J. As primeiras penetrações portuguesas em África. In: ALBUQUERQUE, L. (orgs.). Portugal no mundo. Vol.1, Lisboa: Publicações Alfa, 1989, p.281-299.

DUARTE, M.E.L. Variação e sintaxe: clítico acusativo, pronome lexical e categoria vą̧ia no português do Brasil. Dissertação de mestrado - PUC, São Paulo, 1986.

FIGUEIREDO, C. O objeto direto anafórico no dialeto rural afro-brasileiro. Dissertação de mestrado - UFBA, Salvador, 2004.

Figueiredo, C.F.G. Linguística, história, antropologia e ensino no Kwanza Sul, Angola. "Projeto Libolo" - Município do Libolo, Kwanza-Sul, Angola: aspectos linguísticoseducacionais,histórico-culturais, antropológicos e sócio-identitários. Vol 1. Lisboa: Chiado, 2015.

FIGUEIREDO, C.F.G. Aspectos histórico-culturais e sociolinguísticos do Libolo: aproximações com o Brasil. In: OLIVEIRA, M.S.D.; ARAUJO, G.A. O Português na África Atlântica. Humanitas: FAPESP, 2018, p. 47-97.

FIGUEIREDO, C.F.G. \& OLIVEIRA, M.S.D. Português do município do Libolo, Angola, e português étnico da comunidade de Jurussaca, Brasil: cotejando os sistemas de pronominalização. PAPLA, São Paulo, n. 23(2), p. 105-185, 2013.

FIGUEIREDO SILVA, M. C. A perda do marcador dativo e algumas de suas conseqüências. In: CASTILHO, Ataliba T. de et alii (Org.). Descrição, História e Aquisição do Português Brasileiro. São Paulo: Fapesp, Campinas: Pontes Editores, 2007, p. 85-110.

LOPES, N.S.; SOUZA, C.M.B.; ALVARENGA, V.S. Os dativos em Luanda (Angola) e em Piranga (Minas Gerais). Interdisciplinar, Aracaju, Ano XI, v.24, p. 61-72, 2016.

MIGUEL, M.H. Dinâmica da pronominalização no português de Luanda. Luanda: Editorial Nzila, 2003.

MINGAS, A.A. Interferência do kimbundu no português falado em Lwanda. Porto: Campo das Letras, 2000. 
NZAU, D.; VENÂNCIO, J.C.; SARDINHA, M.G. Em torno da consagração de uma variante angolana do português: subsídios para uma reflexão. Limite, p. 159-180, 2013.

REDINHA, J. Etnias e culturas de Angola. Coimbra: AULP, 2009.

SANTOS, E.F. Sentenças marcadas para o foco no Português do Libolo: uma proposta de análise derivacional. Tese de Doutorado - USP, São Paulo, 2015.

SANTOS, E.F. Aspectos da língua portuguesa em Angola. PAPIA, São Paulo, n.28(1), p.25-49, 2018.

TORRES MORAIS, M.A.C.R. \& BERLICK, R.A. Eu disse pra ele ou disse-lhe a ele: a expressão do dativo nas variedades brasileira e europeia do português. In: CASTILHO, A.T. et al. (orgs.) Descrição, história e aquisição do português brasileiro. São Paulo: Pontes/FAPESP, 2007, p.61-74.

Recebido em: 28/10/2019

Aprovado em: 07/12/2019

Publicado em: 30/04/2020 